\title{
La polémica sobre los símbolos religiosos en Francia. La laicidad republicana como principio de integración ${ }^{1}$
}

\author{
Carmen Innerarity \\ Universidad Pública de Navarra \\ carmeni@unavarra.es
}

RESUMEN

ABSTRACT

La discusión sobre cuál es el modo más adecuado para lograr la integración de los inmigrantes se ha reavivado recientemente en Francia como consecuencia de las reivindicaciones de algunos grupos culturales en las escuelas. Si tradicionalmente Francia había adoptado un modelo de integración basado en la asimilación voluntaria junto al respeto a las prácticas culturales privadas, en los últimos años el debate se ha visto dominado progresivamente por quienes pretenden reafirmar la laicidad republicana como la forma más adecuada de lograr la convivencia dentro de la diversidad cultural y religiosa. En este artículo se expone la evolución del debate sobre los símbolos religiosos en las escuelas en Francia. Un debate que ha pasado desde la tolerancia inicial a su reciente prohibición por ley, a partir de las recomendaciones del Informe de la Comisión Stasi, pero basando siempre la argumentación en la laicidad de las instituciones.

Palabras clave: Integración Cultural, Educación, Laicidad, Francia.
As a result of the claims made by a number of cultural groups in schools, there has recently been a revival in France of the debate about the most appropriate way to achieve the integration of immigrants. While France has traditionally adopted a model of integration based on voluntary assimilation together with respect for private cultural practices, during the last few years the debate has been increasingly dominated by those who wish to assert republican laicity as the most appropriate way of achieving peaceful co-existence in the midst of cultural and religious diversity. This article examines the development of the debate over religious symbols in French schools. A debate which began from a standpoint of tolerance and has now resulted in the recent legal ban on religious symbols on the basis of recommendations made by the Stasi Committee's report and on an argument about the laicity of institutions.

Keywords: Cultural Integration, Education, Laicity, France.

1 Este artículo se enmarca dentro de un proyecto de investigación sobre multiculturalismo y educación, financiado por el Gobierno de Navarra, dirigido por la autora de este artículo. 

La situación generada en Francia como consecuencia del atrincheramiento en guetos de las comunidades de inmigrantes, del repliegue comunitario en busca de seguridad ante un mundo cargado de incertidumbres y de las reivindicaciones identitarias de esos grupos en el ámbito público, sobre todo en la escuela, los hospitales y las Administraciones públicas, ha reavivado el debate sobre cuál es el modo más adecuado para lograr la integración de los inmigrantes. El modelo de integración tradicionalmente adoptado en Francia es el de la asimilación voluntarista, matizada por la tolerancia respecto a las prácticas privadas de la diversidad. Pero, desde los años ochenta, el debate sobre esta cuestión ha ido siendo dominado progresivamente por los defensores de un republicanismo radical, que proponen reafirmar la laicidad de las instituciones, como un aspecto concreto de la neutralidad del Estado, por considerar que ésta sería la forma más adecuada de lograr la convivencia dentro de la tolerancia y el respeto por la diversidad cultural y religiosa.

Las formas de acomodo social y político del pluralismo religioso han ido cambiando en función de los diferentes contextos históricos, sociales y políticos. La separación entre Iglesia y Estado, entre política y religión, ha adoptado distintas formas en las sociedades contemporáneas en función de la historia de cada país. Uno de los principios rectores de la política francesa de integración de la diversidad ha sido y continúa siendo la laicidad republicana, que establece una radical separación entre ambas instancias. En los últimos años ha adquirido un notable protagonismo en el debate político y social acerca de la mejor manera de integrar en la sociedad francesa a los inmigrantes procedentes de países islámicos, a raíz de la llamada «guerra del velo». Voy a exponer aquí los aspectos principales del contenido del principio de laicidad, tal y como se desprende de la respuesta política dada a la polémica sobre los símbolos religiosos en las escuelas públicas en los distintos momentos de su desarrollo.

\section{LOS ORÍGENES DE LA CONTROVERSIA SOBRE LA LAICIDAD}

La laicidad republicana surge en un contexto social y político que tiene poco que ver con la integración de las culturas. Es el momento de terminar con el Antiguo Régimen y con la alianza entre la Iglesia católica y el poder político. Por esta razón tiene un carácter combativo, de manera especial, respecto a la religión católica. Ese tono antirreligioso del laicismo francés, que también se ha desarrollado en otros países de tradición católica, está ausente, en cambio, en Estados Unidos y en los países de tradición protestante del norte de Europa. Esta diferencia se debe a que en muchos de estos países la diversidad, dispersión y fragmentación de las comunidades religiosas reformadas no permiten a ninguna de ellas establecer una especial alianza con el poder político. Nacida en unas circunstancias concretas, la laicidad va a pasar a formar parte de la identidad nacional francesa, adaptándose a los cambios que ha experimentado la sociedad en Francia. 
La laicidad se deriva en última instancia del artículo 10 de la Declaración de los Derechos del Hombre y del Ciudadano, del 26 de agosto de 1789, que establece que «nadie puede ser molestado a causa de sus opiniones, incluidas las opiniones religiosas». Pocos años después de esta declaración, el Concordato suscrito entre Napoleón Bonaparte y el Papa Pío VII el 15 de julio de 1801 fija el estatuto de la Iglesia y define a la religión católica como «la religión de la gran mayoría de los franceses», pero no como la verdadera religión ni como la religión del Estado. El Concordato fija también el principio de la libertad de cultos. Una serie de leyes posteriores establecerán un estatuto específico para las Iglesias protestantes y para el judaísmo.

Tras el hundimiento del imperio de Napoleón III y el acceso al poder de una mayoría republicana en 1879 comienzan las medidas para una laicización de la sociedad francesa, como la autorización del divorcio, la secularización de los cementerios y, de manera especial, la lucha contra las congregaciones religiosas dedicadas a la enseñanza y la extensión de la enseñanza pública, impulsada por Jules Ferry².

La laicidad queda sancionada legalmente por la Ley de 9 de diciembre de 1905, una Ley de separación entre Iglesia y Estado, que establece en su artículo 1. : «La República asegura la libertad de conciencia. Garantiza el libre ejercicio del culto, con las únicas restricciones que se establecen a continuación en interés del orden público». Y en el artículo 2. ${ }^{\circ}$ señala que «la República no reconoce, no paga salarios ni subvenciona ningún culto». Es decir, la laicidad del Estado se deriva de la libertad de conciencia de los ciudadanos, y esa libertad está limitada por el respeto al orden público. Esta declaración del carácter limitado de la libertad de conciencia va a estar muy presente, como veremos, en toda la polémica sobre los símbolos religiosos en la escuela. La Ley establece también el estatuto de las asociaciones con una finalidad religiosa y regula el régimen de propiedad de los bienes pertenecientes a dichas asociaciones ${ }^{3}$. Las declaraciones de principios y las disposiciones de la Ley de 1905 serán completadas poco después por la Ley del 2 de enero de 1907 sobre el ejercicio público de los cultos.

La Ley de 1905 no es propiamente una Ley de laicización del Estado, es una Ley de privatización y liberalización. Privatiza el culto en el sentido en que se puede privatizar una empresa como la Renault, es decir, no la excluye de la vida social, sino que le retira su estatus público (Poulat, 2003). Según los términos de la Ley, la religión no es un asunto completamente privado, ya que «el Estado garantiza el libre ejercicio de los cultos» (art. 1. ${ }^{\circ}$ ). Lo que

\footnotetext{
2 La Ley Ferry, del 28 de marzo de 1882, instituye la escuela pública gratuita y laica, así como la enseñanza obligatoria. La instrucción moral y religiosa es sustituida por la instrucción moral. La Ley Goblet, del 30 de octubre de 1886, establece que la enseñanza en las escuelas públicas debe ser impartida por personal laico.
}

${ }^{3}$ Esta Ley no se aplica en la región de Alsacia-Mosela, que se rige por un Concordato específico, ni en la Guyana y Polinesia. 
se produce aquí es una privatización de la religión, en dos sentidos. Por un lado, significa que las diferentes confesiones no pueden hacerse cargo de actividades de servicio público $y$, por otro, que los servicios públicos estatales no pueden estar marcados por ninguna pertenencia religiosa. La vida religiosa se reduce, así, a sus expresiones rituales y se convierte en una confesión. Algo muy diferente de la visión británica o la alemana, que reconocen a las religiones un lugar y un papel en la sociedad. Por ello, no resulta falso afirmar que Francia es el único país laico de Europa en el sentido más estricto (Cesari, 2001: 128).

Después de que el Gobierno de Vichy derogara en 1941 la Ley de 1905 y adoptara, entre otras medidas, la reintroducción de la enseñanza de la religión en la escuela pública y la concesión de subvenciones públicas a la enseñanza católica, el principio de laicidad quedará recogido por la Constitución de 1946, votada tanto por comunistas y socialistas como por los demócrata-cristianos. Es un principio recogido igualmente en la Constitución de 1958. En ambas Constituciones se define a Francia como una «República laica», lo que indica que la laicidad constituye una forma - y un proyecto - de organización de la sociedad, que no se reduce al ámbito escolar, aunque éste sea un campo esencial de aplicación.

Un siglo después de la Ley de 1905, la laicidad se ha convertido en un valor aceptado en Francia por creyentes y no creyentes. La secularización de la sociedad y la desafección religiosa son procesos que han contribuido al consenso en torno a la laicidad. Ahora es el Islam, percibido como la religión «del otro», el que plantea dudas e interrogantes. Por eso, cuando empiezan a surgir los primeros conflictos en la década de los ochenta, nadie pone en duda el carácter laico de la escuela. Por eso, por ejemplo, cuando el Ministro del Interior, Nicolás Sarkozy, señala en su locución ante la Comisión Stasi que las mujeres deben llevar la cabeza descubierta en las fotos del carnet de identidad, apela al orden público, no a la laicidad, que considera que está fuera de toda duda. Cuando se impulsa la educación mixta, se hace a partir de la igualdad entre niños y niñas, no de la laicidad (Gresh, 2003), que es algo ya arraigado en la sociedad francesa. Los problemas se plantean durante todo este tiempo al interpretar qué significa esa laicidad y cuáles son sus consecuencias prácticas a la hora de aplicarla al trato con la comunidad musulmana.

Si ahora surge la necesidad de una nueva reflexión sobre la laicidad es por un doble motivo. Por un lado, se deriva de las nuevas circunstancias de los países europeos, que se enfrentan a la situación provocada por el aumento de la inmigración procedente de países con tradiciones religiosas que hasta el momento no tenían tanta fuerza en los países de acogida, y a que los grupos formados por esos inmigrantes expresan su malestar social mediante reivindicaciones de carácter cultural y religioso. Y la segunda razón que justifica la necesidad de esa reflexión es que no hay una definición clara acerca de qué hay que entender por laicidad. Ni la Ley de 1905 ni las Constituciones de 1946 y 1958 definen qué es 
la laicidad; de ahí que cuando empiezan a surgir los primeros casos de niñas que acuden a la escuela con velo, no haya un criterio claro sobre cómo hay que proceder conforme a ese principio. Por eso, dado el acuerdo acerca del carácter laico de la sociedad francesa y de sus instituciones, los conflictos que han surgido en este terreno desde su constitucionalización en 1946 pueden calificarse como "conflictos de interpretación» (Baubérot, 2001: 46), que han llevado a una nueva reflexión para tratar de fijar su significado, de acuerdo con las nuevas circunstancias sociales.

\section{EL DOBLE CONTENIDO DE LA LAICIDAD}

Si en su origen el término «laico» designa a un cristiano bautizado que no pertenece a ninguna congregación religiosa ni está revestido de órdenes eclesiásticas, a partir de la segunda mitad del siglo XIX, cuando empiezan a extenderse las instituciones educativas que no están vinculadas a ninguna orden religiosa, la laicidad es entendida como una doctrina que mantiene la neutralidad respecto a las diferentes confesiones religiosas y filosóficas, de manera especial en el ámbito de la escuela. De forma más genérica y a nivel institucional, designa la separación entre el ámbito de la política y el de la religión (éste es el significado que se desprende de la Ley de 1905 sobre la separación entre las Iglesias y el Estado en Francia). Pero no hay un acuerdo acerca de la manera en que lo político y lo religioso deben estar separados, en particular, en la escuela pública. Existen, fundamentalmente, dos posturas al respecto. La primera considera que la laicidad significa la ausencia de todo signo y manifestación religiosos en el seno de las instituciones revestidas de algún tipo de autoridad pública. Para la otra postura, en cambio, la laicidad en el medio escolar implica únicamente que los maestros y profesores no manifiesten sus creencias religiosas y que la enseñanza no esté sesgada en función de dichas creencias. Esto no impide que los alumnos lleven algún signo religioso, a partir de la libertad de opinión y expresión, que incluye también la libertad religiosa. Los debates actuales confrontan estas dos maneras de entender la laicidad. Pero su imbricación con cuestiones de integración y de identidad no ha ayudado a su clarificación, al tiempo que ha favorecido una focalización, de manera específica, sobre las relaciones entre el Islam y la República.

¿Qué hay en el concepto de laicidad que permite interpretaciones contrapuestas a la hora de aplicarlo a los conflictos concretos? Considero que un punto de partida apropiado para analizar este problema lo proporciona la definición propuesta por Émile Poulat (1987), quien señala que la laicidad tiene como fundamento la emancipación de la noción de libertad respecto a la de verdad. Pero esa libertad puede revestir dos formas diferentes: libertad de conciencia y libertad de pensamiento. La libertad de conciencia significa un ideal de igualdad, no sólo entre las distintas pertenencias religiosas, sino también entre la perte- 
nencia a una comunidad y la no pertenencia, incluso militante. La libertad de conciencia es sobre todo una libertad de carácter individual, aunque puede prolongarse en ciertos derechos colectivos. Pero la laicidad francesa está marcada por la lucha contra las formas religiosas consideradas autoritarias e intolerantes; por ello, no es solamente libertad de conciencia, sino también libertad de pensamiento. No se trata sólo de una libertad que dé origen a una diversidad de convicciones, a un pluralismo religioso, sino de una libertad considerada como emancipación respecto a toda doctrina omniabarcante, emancipación guiada por la razón y la ciencia, emancipación de las particularidades que pudieran impedir la realización del ideal abstracto de ciudadanía. De ahí que las distintas declaraciones sobre esta cuestión apelen siempre a la idea de una «República indivisa» (Constitución de 1946), a que la laicidad es lo que «permite a los ciudadanos identificarse con la República, con el fin de poder vivir juntos» (Informe de la Comisión Stasi, 1.2.2).

Pero es ese doble aspecto de la laicidad lo que da lugar a posturas divergentes al aplicarla a los casos concretos. La laicidad entendida como libertad de conciencia justifica la defensa del uso del pañuelo, como una manifestación suya, pero, en cambio, se ataca esta práctica en virtud de la laicidad como libertad de pensamiento, por considerarla un símbolo de opresión de la mujer, una manifestación de una religión que impide la emancipación de la mujer y que, además, pondría en peligro la unidad de la República, al dificultar la interiorización de los valores compartidos de la ciudadanía.

Estas son las dos posturas enfrentadas en el debate sobre los símbolos religiosos en la escuela, por ser una institución clave de la laicidad, ya que es el lugar privilegiado donde se puede llevar a cabo esa emancipación y el aprendizaje de la ciudadanía. La autonomía se promueve en una escuela laica, que no es una escuela antirreligiosa, pero sí una escuela libre de todo grupo de presión, del tipo que sea, religioso, ideológico o económico. La laicidad es un ideal positivo, no reactivo: pone el acento en lo que es común a todas las personas, más allá de sus diferencias. Por eso, no conduce a un rechazo de la religión, sino del clericalismo, de la alianza entre poder político y religioso, y, en la cuestión que ahora nos ocupa, en el carácter proselitista que puedan tener determinados símbolos y comportamientos.

\section{EL ISLAM EN FRANCIA Y LA INTEGRACIÓN REPUBLICANA}

No existen estadísticas seguras sobre el número de musulmanes en Francia, debido, entre otras razones, a la prohibición de incluir preguntas sobre las creencias religiosas en las encuestas oficiales. Pero distintos estudios señalan la cifra de entre cuatro y cinco millones (Ramadan, 2002: 172). 
A partir de la década de los setenta, tras el proceso de descolonización y la llegada masiva de personas procedentes de países de tradición islámica, la integración de las comunidades inmigrantes en Francia experimenta un cambio respecto a épocas anteriores. Van a cambiar tanto la situación del Islam en Francia como la opinión pública y la actitud de la clase política respecto a la posibilidad y la manera de lograr la integración de los inmigrantes de tradición islámica.

Ahora, el Islam en Francia ya no es la confesión religiosa de personas individuales, sino también un Islam de familias, de grupos, que se van a enfrentar a un mismo tipo de problemas y que van a crear lazos comunitarios basados en la identidad religiosa. Los problemas sociales que afectan a la población musulmana y el desarrollo de un islamismo político-religioso van a alterar profundamente la situación de la comunidad musulmana en Francia ${ }^{4}$.

A finales de esa década empieza a cuestionarse la eficacia del modelo de integración republicano, basado en la escuela pública, donde los niños aprenden los valores fundamentales de la ciudadanía. Hasta ese momento, la asimilación no era vista como un proceso unilateral, sino que quienes se incorporaban a la comunidad política consideraban ese acceso a una ciudadanía abstracta y homogeneizadora como un medio de promoción y de movilidad social, como una fuente indirecta de ventajas materiales, y una vía para lograr un determinado estatus. Pero la llegada masiva de personas procedentes de las antiguas coIonias, unida al aumento del desempleo, especialmente entre la población inmigrante, llevan a poner en duda la creencia en el universal del Estado-nación y de los símbolos que lo conforman como un medio de integración social. Quienes proceden de las antiguas colonias, en su mayoría musulmanes, no son ciudadanos como los demás. La distinta situación social de personas en función de sus orígenes lleva a tomar conciencia de los límites de la integración republicana y la ciudadanía universal y genera un malestar entre la población inmigrante, que recurre a reivindicaciones identitarias para demandar mejoras sociales.

Por otra parte, el Islam tiene diversas caras en Francia. Existe, en primer lugar, un Islam individualizado, que no se manifiesta públicamente porque acepta la distinción entre lo público y lo privado, profesado por personas de tradición musulmana socialmente integradas, que abandonan los barrios periféricos para incorporarse al espacio urbano de las clases medias. En los últimos diez o quince años ha surgido también un Islam neocomunitario,

\footnotetext{
${ }^{4}$ La ausencia de una jerarquía musulmana es vista como un obstáculo para la integración. El Islam no tiene una jerarquía que pueda organizar y movilizar a las comunidades musulmanas en Francia. Por eso, el Estado laico trata de organizar un «Islam francés», por ejemplo, mediante la construcción de mezquitas. De ahí también el empeño de Nicolas Sarkozy, siendo Ministro del Interior, por crear un órgano representativo, el Consejo del Culto Musulmán, que ha contribuido al diálogo y el entendimiento entre el Islam y la República. Este organismo está presidido por Dalil Boubaker, moderado, pero en minoría dentro del Consejo, controlado por la Unión de Organizaciones Islámicas de Francia, presidida por Lahj Thami, próximo a los Hermanos Musulmanes, de tendencia radical.
} 
profesado por jóvenes de segunda y tercera generación, ya instalados en Francia, distinto del Islam tradicionalista y popular, muy asociado a tradiciones étnicas, de las generaciones que llegaron como inmigrantes. Una gran parte del Islam de esos jóvenes se construye sobre un fondo de malestar social, económico y cultural, de exclusión social y pobreza. Como afirma Ramadan, «un buen número de ellos desean (re)afirmar su identidad y vivir según las enseñanzas del Islam. Tras una infancia difícil, redescubren su origen y su religión» (Ramadan, 2002: 164). La religión constituye una fuente de sentido para quienes no pueden participar en la vida social como ciudadanos de pleno derecho. Sin empleo, sin posibilidades de prosperar y sin ideologías que permitan soñar en un mundo distinto, la religión constituye una atractiva oferta de integración social y esperanza individual. Se trata de un Islam «defensivo», de «rechazo» (Samadi, 2003), que les permite crear estructuras asociativas y redes sociales fundadas en la religión. La adopción de este Islam neocomunitario permite escapar a la marginalidad y proporciona a los jóvenes «conversos» una identidad «fuerte», basada en normas y referencias comunes. Esta circunstancia favorece la constitución de comunidades en el espacio público basadas en la identidad religiosa compartida. Son dos formas diferentes de una misma religiosidad, pero tienen en común el ser un Islam en Francia, en el sentido de que comparten aspiraciones y también las frustraciones de las generaciones nacidas y escolarizadas en Francia.

El Islam activista de los jóvenes musulmanes es un Islam ostentatorio y reivindicativo, no sólo de prácticas culturales, sino también de una situación de exclusión social, que quiere manifestarse incluso en el templo de la laicidad francesa que es la escuela pública. Esto es visto por la opinión pública mayoritaria como una prueba de que su integración resulta imposible. Aunque a finales de los ochenta la integración es mayor, la percepción social del pluralismo asociado a la inmigración como un valor se ve sustituida progresivamente por una visión negativa de la diversidad procedente de países de tradición islámica, cuya integración se va viendo cada vez más como algo imposible de alcanzar.

La evolución que experimentan la opinión pública y la clase política francesas respecto a la integración de los inmigrantes, y más en concreto en relación con la laicidad de la escuela, es descrita en los siguientes términos por Jack Lang, Ministro de Cultura de 1981 a 1986 y de 1988 a 1993 y, posteriormente, Ministro de Educación entre 2000 y 2002. En una entrevista concedida a L'Express explicaba así la evolución de la izquierda, tradicionalmente más proclive al respeto a las diferencias culturales. «En 1989 o en 1995 no éramos conscientes de los peligros del extremismo islámico..., en los años ochenta y noventa se ponía el acento en el mestizaje, el pluralismo... Existía la creencia de que ese mestizaje de las diferencias sería fecundo y llevaría a ser tolerantes con los particularismos» (Lang, 2003). Predominaba entonces una ideología que privilegia la diferencia y el pluralismo y que, en consecuencia, no veía la urgencia de reconstruir mediante la educación un mundo común, 
de crear referencias compartidas, y de privilegiar los valores comunes por encima de las diferencias comunitarias.

Se podría establecer, entonces, una correlación entre los errores de la política de integración durante los años ochenta y el desarrollo paralelo de las reivindicaciones identitarias y, más en concreto, de la cuestión del velo. Ésta es, por ejemplo, la tesis defendida actualmente por Hanifa Cherifi, que ha actuado desde 1994 como mediadora entre el Ministerio de Educación Nacional y las jóvenes que llevaban velo. En su opinión, la falta de atención suficiente a la inserción laboral de los inmigrantes ha preparado el terreno para el desarrollo del islamismo. "Un terreno en el cual han prosperado los islamistas y en el que la cuestión del velo es solamente un síntoma... Lo grave es que el islamismo ofrece un modelo alternativo a la integración, el de la familia musulmana ortodoxa, en la que el Corán establece el lugar de la mujer y no la idea de ciudadanía. Ante la ausencia de otras respuestas, las mujeres sacrifican su libertad en beneficio de la cohesión de la comunidad» (Cherifi, 2001).

Por otra parte, el Islam no se encuentra en las mismas condiciones que las demás religiones en Francia, tal y como lo expresaba recientemente ante la Comisión Stasi el Ministro del Interior, Sarkozy. «Todavía existe el Islam de las cuevas y los garajes. Estamos pagando ahora nuestro desinterés de ayer». Hay escasez de mezquitas, de enterramientos musulmanes en los cementerios, no hay clérigos musulmanes en las escuelas, ni un instituto para la formación de imanes en Francia. «Esta realidad, unida a la desastrosa política urbana y social que ha acompañado a la inmigración masiva de los años cincuenta y sesenta, ha provocado un rechazo del modelo francés de integración, de nuestros valores, sobre el que se han desarrollado los extremismos». Como el acceso a la sociedad francesa en igualdad de condiciones les es, en parte, imposible, o muy difícil, o lento, el velo es el medio para afirmar una identidad diferente. $Y$ el problema es que «una identidad humillada es una identidad radicalizada»

Una forma de expresar el descontento y un aspecto de esta lucha por la manifestación pública del Islam es la demanda de las jóvenes musulmanas, presionadas en muchos casos por esas comunidades identitarias a las que pertenecen, respecto a la exención de las normas de indumentaria en las escuelas. Según la tipología de Kymlicka (1997), esta reivindicación se incluye dentro de los llamados derechos poliétnicos. Son derechos cuya finalidad es «ayudar a los grupos étnicos y a las minorías religiosas a que expresen su particularidad y su orgullo cultural sin que ello obstaculice su éxito en las instituciones económicas y políticas de la sociedad dominante» (Kymlicka, 1997: 53), es decir, no buscan la exención por la exención, sino la posibilidad de conservar las propias tradiciones culturales o religiosas, sin que ello sea un obstáculo para su integración en la sociedad en las mismas condi- 
ciones que el resto de los ciudadanos. No son derechos temporales, que deban estar vigentes hasta que se supere una determinada situación de desigualdad, sino que tienen un carácter permanente, ya que las diferencias culturales que protegen y donde los marginados encuentran seguridad no son algo que se pretenda eliminar. Pero, a diferencia de otro tipo de acomodos de la diversidad, como los derechos de autogobierno, su finalidad es fomentar la integración en el conjunto de la sociedad.

Por eso, lo que está en juego es el modelo tradicional de integración republicana, basado en la asimilación, que establece una equivalencia entre nacionalidad, ciudadanía y comunidad cultural. En palabras de Ramadan, «el proyecto de asimilación preveía una total identificación del inmigrado con el nuevo universo cultural que le acoge y el olvido de sus referencias, para introducirse de la manera más completa en su nuevo paisaje» (Ramadan, 1994: 164). Frente a este modelo se alzan las demandas que pretenden poder continuar con las propias prácticas religiosas en una sociedad en la que, por los motivos que he mencionado anteriormente (el aumento en número y la «re-islamización» de los jóvenes), el Islam se ha hecho más visible.

\section{EL CONFLICTO DEL VELO EN LA ESCUELA}

Éste es el contexto en el que surge la controversia sobre el velo en Francia. Tiene su origen en 1989, cuando unas alumnas del colegio Gabriel Havez, de Creil, una ciudad situada al norte de París, se niegan a acudir a clase con la cabeza descubierta. Este acontecimiento desencadena vivos debates sobre la laicidad en la escuela. Los poderes públicos actúan inspirados por el Dictamen del Consejo de Estado del 27 de noviembre de 1989, que irá seguido por la Circular Jospin, del 12 de diciembre de 1989.

El Dictamen del Consejo de Estado considera que el velo no atenta contra la laicidad y que las alumnas pueden llevarlo si lo desean, en virtud de la libertad de conciencia. No es que el Consejo autorice el uso del velo, sino que únicamente precisa en qué condiciones puede aceptarse sin atentar contra la laicidad. El Consejo dice expresamente que «llevar signos religiosos no es en sí mismo incompatible con la laicidad, a condición de que no tengan un carácter ostensible o reivindicativo, de forma que pudieran perturbar el funcionamiento del servicio público y que no constituyan un acto de presión, provocación, proselitismo o propaganda». Cada caso deberá ser estudiado de manera individual, sin ver a priori detrás de cada foulard a una joven extremista, manipulada y que exhibe de forma ostentatoria un signo religioso. A partir de entonces se establece un modus vivendi en el que el pañuelo es tolerado en algunos centros, en unos casos en todo momento, en otros solamente en unos espacios y tiempos determinados. Pero aunque este Dictamen va a constituir durante mu- 
cho tiempo la referencia jurídica fundamental sobre la cuestión del velo islámico, no ofrece una respuesta que permita actuar de manera uniforme en todos los casos que se plantean. Por eso, va a traer como consecuencia un aumento del número de niñas que acuden a la escuela con la cabeza cubierta y la prolongación del debate abierto por el incidente de las alumnas de Creil.

Para responder a la polémica creada, el entonces Ministro de Educación, Lionel Jospin, envía una Circular a los directores de los centros escolares el 12 de diciembre de 1989 en la que, basándose también en la laicidad como libertad de conciencia, autoriza a llevar signos religiosos en la escuela, siempre que no tengan un carácter reivindicativo y que no obstaculicen el buen funcionamiento de las actividades educativas. Afirma que «la laicidad, principio constitucional de la República, es uno de los fundamentos de la escuela pública». Pero señala, al mismo tiempo, que «llevar signos religiosos no es en sí mismo incompatible con el principio de laicidad, en cuanto que se deriva del ejercicio de la libertad de expresión y manifestación de las creencias religiosas recogido en la Constitución, los tratados internacionales suscritos por Francia y los principios fundamentales reconocidos por las leyes de la República». En continuidad con el Dictamen del Consejo de Estado francés de noviembre y en la misma línea que la Ley de 1905, declara también que la libertad de expresión no tiene un carácter absoluto, sino que está limitada «por el respeto a la libertad de los demás y a los principios de organización y funcionamiento» de la escuela ${ }^{5}$. Por ello, no sería admisible llevar signos religiosos que por su carácter ostensible o reivindicativo constituyeran un acto de presión, provocación, proselitismo o propaganda, que pudieran atentar contra la dignidad o la libertad de los miembros de la comunidad educativa, que pusieran en peligro su salud o su seguridad, obstaculizaran el desarrollo de las actividades educativas; en definitiva, que de algún modo perturbaran el orden en la institución educativa pública. Por eso no se puede establecer una ley general, sino que cada caso problemático deberá ser evaluado individualmente y recomienda solucionarlo mediante el diálogo con los alumnos y con sus padres. Insiste en la necesidad de no perder de vista que los consejos escolares no son un tribunal, sino una instancia educativa. Bayrou dejaba, así, en manos de los directores de cada centro la responsabilidad de decidir qué era proselitismo o provocación, insistiendo en que el espíritu de la educación republicana era igualitario y que, por tanto, había que impedir la «automarginación» de los alumnos por la vía del vestido.

La Circular no se limita exclusivamente al tema del velo, sino que también establece la obligatoriedad de la asistencia a clase, ante la negativa de algunos alumnos de acudir, por

\footnotetext{
5 Llama la atención que en ningún momento se hace referencia a la Convención Internacional de los Derechos de la Mujer, suscrita por Francia en 1984, cuyo artículo 2 establece que los Estados signatarios se comprometen a adoptar las acciones y disposiciones legales necesarias para modificar o derogar cualquier ley, costumbre o práctica que constituya una discriminación para las mujeres, lo cual tendría que haber llevado a la prohibición del velo en todos los casos.
} 
ejemplo, a las clases de historia en las que se explican determinados temas como el holocausto, o a clases de gimnasia. Finalmente, recuerda también la obligación de los maestros de respetar el principio de laicidad, que les impide privilegiar de algún modo cualquier doctrina política, filosófica o religiosa, de forma que pudieran atentar contra la libertad de conciencia de los alumnos.

Vemos, entonces, cómo la Circular de Jospin alude a la necesidad de salvaguardar el orden y la unidad de la República y considera la laicidad como un medio necesario para lograr ese objetivo. Y, además, en ella están implícitas las dos dimensiones de la laicidad. La libertad de conciencia permite que los alumnos acudan a la escuela con signos religiosos. Pero, al mismo tiempo, la libertad de pensamiento impide que éstos tengan un carácter proselitista e impone a los maestros la obligación de no impartir una enseñanza con un sesgo ideológico del tipo que sea.

A partir de aquí surge la polémica en distintos sectores de la sociedad francesa, que se apoyan en uno u otro aspecto de la laicidad. Por un lado, la izquierda, que considera que esa disposición atenta contra la laicidad, y las organizaciones feministas, que enarbolan la bandera de la defensa de la igualdad de las mujeres; por otro, los defensores de la diversidad cultural y el pluralismo religioso.

Después de los incidentes de Creil, los casos se repiten. Pero la Circular Jospin dejaba al arbitrio de los centros juzgar sobre el carácter ostentoso o no de los signos. Además, los gobiernos franceses posteriores habían dejado pasar el tema del velo sin legislar sobre ello. Por otra parte, existían sentencias judiciales contrapuestas en este terreno. Hay, por ejemplo, una sentencia que confirma la exclusión de dos jóvenes con velo de un colegio de Nantua; otra, sin embargo, exige el reingreso de unas adolescentes en un liceo de Vendôme. Existe, en concreto, una intervención del Consejo de Estado en noviembre de 1992 que anula la expulsión de tres alumnas de un colegio en Motfermeil que se habían negado a quitarse el velo para asistir a clase. Esta intervención va a tener una gran importancia ya que propiciará la multiplicación de los conflictos. Por eso, los directores de los centros escolares piden indicaciones concretas sobre la manera de afrontar el problema.

En estas circunstancias, François Bayrou, Ministro de Educación del Gobierno socialista de Edouard Balladur, envía una carta el 20 de septiembre de 1994 con la intención de proporcionar a los directores de los centros indicaciones más concretas acerca de cómo proceder de forma coherente en los casos conflictivos. La Circular Bayrou expresa la preocupación ante el riesgo de que una ciudadanía republicana respetuosa, al mismo tiempo, con las diferencias culturales llevada a sus extremos pueda poner en peligro la unidad de la nación. Por eso señala que el ideal francés de ciudadanía implica el respeto por todas las convic- 
ciones, de manera especial las convicciones religiosas, políticas y las tradiciones culturales, pero, al mismo tiempo, excluye la división de la nación en comunidades diferentes que coexisten separadas las unas de las otras. «La nación no es solamente un conjunto de ciudadanos portadores de derechos individuales, sino que es una comunidad de destino". Y este ideal se forja en la escuela. La escuela es el lugar en el que los niños aprenden a vivir juntos y a respetarse mutuamente. La presencia de signos y comportamientos que pudieran indicar una discriminación por razón del sexo, la cultura o la religión en cuanto al cumplimiento de unas obligaciones iguales para todos atentaría contra la misión de educación cívica esencial a la escuela. Por eso, no se puede aceptar el uso de prendas y signos ostentosos cuyo sentido es separar a los niños de las reglas comunes del centro. Se opone a que las niñas lleven la cabeza cubierta a clase, por considerarlo como un «signo ostentoso de diferenciación que crea separación entre los jóvenes». Además, argumenta, «la fe es un asunto privado y la sociedad debe mantener su unidad y laicidad, muy especialmente en el ámbito sensible de la escuela» (Circular Bayrou).

Por eso, recomienda a los directores de los centros incluir en los reglamentos la prohibición de signos religiosos ostentosos, que puedan tener por sí mismos un carácter de proselitismo o de discriminación, todo tipo de presión sobre los alumnos, así como cualquier comportamiento que pueda poner en peligro su seguridad o perturbar el orden del centro. Continuando con la línea abierta por Jospin, que, por otra parte, ha estado muy presente en el debate actual, insta al diálogo con las familias de forma que no se impida la escolarización, ya que ésta constituye el principal camino para la formación de una personalidad autónoma.

Una vez más, el orden y la unidad de la República constituyen el hilo argumental de la laicidad. La carta de Bayrou es un claro exponente de la cultura cívica francesa, que «busca su fuerza en la competencia universal y anónima regulada por una absoluta igualdad en las reglas; la fuente de toda libertad es la igualdad y la fe compartida en la razón como tal» (Baumann, 2001: 67). Parece que se espera que todas las minorías compartan esta fe en el culto centralista y colectivo hacia una racionalidad metarreligiosa. Si los revolucionarios franceses hicieron de la catedral de París un templo de la razón, las elites políticas francesas han seguido reinventando esta religión civil de una razón y una ciudadanía abstractas para todos. Este esfuerzo es algo que se puede constatar no solo en la Circular de Bayrou, sino que está presente en una gran parte de los argumentos a los que han recurrido las autoridades estatales de diferente signo a la hora de afrontar la cuestión de los símbolos religiosos en las escuelas y en las Administraciones y la integración de los inmigrantes en general. El valor absoluto de la ciudadanía republicana que sustituye al absolutismo dinástico declara ilegal cualquier tipo de lealtad étnica, cultural o religiosa en favor de la «comunidad de destino» (Circular Bayrou) que es Francia. 
Las disposiciones de la Circular entran en vigor al comienzo del curso 1994 y consiguen que si en ese momento acuden a la escuela 2.000 niñas con la cabeza cubierta, según datos del Ministerio de Educación, en diciembre solamente sean 400 las niñas que se niegan a quitarse el velo. La cuestión del hiyab provoca 79 expulsiones (sobre todo en los colegios de Lille, Estrasburgo, Créteil y Versalles) y casi todas esas niñas continúan sus estudios en el Centro Nacional de Enseñanza a Distancia, según los datos proporcionados entonces por el Ministerio de Educación Nacional.

Tras la Circular Bayrou, la jurisprudencia sigue siendo ambigua ya que aún no existe una normativa general y tanto los Tribunales Administrativos como el propio Consejo de Estado proceden de forma distinta según los casos. Estas fluctuaciones propician la continuación y multiplicación de los conflictos en las escuelas.

La Circular Bayrou es rechazada por distintos sectores políticos y sociales y en los años posteriores continúa abierta la discusión, que no es tanto «velo sí, velo no», sino si hay que poner límites a la libertad de expresión de la identidad religiosa por parte de los alumnos en los centros públicos y de los funcionarios en las Administraciones públicas. Dicho con otras palabras, si la lucha identitaria llevada a la escuela no va a generar una mayor fragmentación social y, en caso afirmativo, hasta qué punto se pueden impedir determinados signos de carácter cultural y religioso. En esta línea, el Informe El Islam en la República, elaborado por el Alto Consejo para la Integración en el año 2000, a petición del entonces Primer Ministro, el socialista Jospin, señala que «ciertos principios como el respeto al otro en su persona y sus convicciones, la igualdad de derechos de los dos sexos, la libertad de expresión y de investigación son intangibles. En particular, para abordar el problema de la escuela, no será tolerable que alumnos o familiares recusen en nombre de una creencia religiosa, tal o cual parte de los programas concernientes a la biología, la literatura, la filosofía, el dibujo o, globalmente, la educación física». El uso del pañuelo es considerado como un recurso identitario que simboliza el rechazo de la laicidad de la escuela pública.

Algunos miembros del Alto Consejo se muestran partidarios de una prohibición general de cualquier símbolo de pertenencia religiosa en la escuela pública porque, en su opinión, «tolerar esa práctica significa aceptar, contra el movimiento general de las sociedades modernas hacia la emancipación de las mujeres, el símbolo de una discriminación eminentemente sexista, atentar contra el principio de laicidad, que instituye en el recinto escolar un espacio de neutralidad destinado a proteger la libertad de los jóvenes, y además, perpetuar las dudas de los directores de los centros escolares y de los maestros enfrentados a estos problemas». Sin embargo, la mayoría de los miembros del Consejo son contrarios a una posible prohibición con carácter general por ley. En primer lugar, porque no estaba claro que una prohibición general estuviera de acuerdo con la Constitución y los acuerdos inter- 
nacionales firmados por Francia. Y, fundamentalmente, porque llevaría a la no escolarización de esas niñas y a su consiguiente confinamiento en los reductos comunitarios, lo cual agravaría el problema al que se quiere hacer frente. Por ello hay un acuerdo en la necesidad del diálogo y la mediación con las niñas que desean llevar la cabeza cubierta y con sus familias. Una idea que está presente desde los orígenes de la controversia y en la que se ha insistido de manera recurrente durante la elaboración y el debate de la Ley de símbolos religiosos de 2004.

\section{EL INFORME DE LA COMISIÓN STASI SOBRE LA LAICIDAD}

El 3 de julio de 2003, la llamada Comisión Stasi, formada por veinte expertos de distintos ámbitos y presidida por Bernard Stasi, Mediador de la República, recibe el encargo del Presidente Jacques Chirac de analizar la cuestión religiosa en Francia desde el punto de vista del principio de laicidad y hacer las recomendaciones oportunas para solucionar los problemas planteados por el uso del velo en las escuelas, que en realidad ha sido el verdadero detonante de esa medida. Las niñas que actualmente acuden a la escuela pública con pañuelo son una minoría. En las escuelas de educación primaria y secundaria estudiaban en el curso 2003/2004 doce millones de alumnos. De ellos, 1.256 chicas llevan velo o pañuelo; se han planteado veinte casos difíciles, que se han saldado con cuatro exclusiones, según los datos recabados en el primer trimestre del curso por los servicios que dependen del Ministro del Interior, Nicolas Sarkozy; bastantes menos que los 3.000 casos con que se encontró el Gobierno de Balladur-Bayrou en 1994, lo cual contradice la idea presente en la opinión pública de que el problema se ha agravado desde entonces.

La Comisión está compuesta por veinte miembros de diversa procedencia: maestros, investigadores, juristas, políticos, directores de centros escolares. La Comisión Stasi publica un Informe el 12 de diciembre de 2003, elaborado tras un intenso trabajo de entrevistas y debates. En él analiza los cambios que ha experimentado la sociedad francesa en el último siglo y señala la necesidad de abordar de una manera nueva la identidad republicana laica, tratando de conciliar la unidad nacional con el respeto a la diversidad, como la estrategia más adecuada para lograr la integración social de los inmigrantes. Pretende reforzar la Ley francesa de 1905 y, apelando al principio de laicidad, recomienda prohibir todo signo religioso ostensible en las escuelas públicas.

La Comisión Stasi ha dado por primera vez una definición elaborada, positiva y abierta de la laicidad. ¿Cuál es el contenido de la laicidad como principio de integración de la sociedad francesa, según el Informe? Para la Comisión, la laicidad «descansa sobre tres valores indisociables: la libertad de conciencia, la igualdad de derechos en cuanto a las opciones 
espirituales y religiosas, la neutralidad del poder político» (Informe Comisión Stasi, Introducción). La libertad de conciencia permite a cada ciudadano elegir una u otra opción espiritual y religiosa, la igualdad de derechos prohíbe toda discriminación o restricción así como que el Estado favorezca a una opción determinada, y, finalmente, en virtud de la neutralidad, el poder político reconoce sus límites y se abstiene de toda intromisión en el ámbito espiritual o religioso.

La laicidad refleja una concepción del bien común: para que todos y cada uno de los ciudadanos puedan integrarse en la República, pretende protegerla del dominio de cualquier opción espiritual o religiosa, con el fin de poder vivir en comunidad. El sentido de la laicidad es «asegurar la igualdad de oportunidades en todo el territorio, el reconocimiento de las diversas historias que componen la comunidad nacional y el respeto a las diversas identidades» (Informe Comisión Stasi, 1.2). Tiene como finalidad poder vivir juntos, construir un destino común. La laicidad no se reduce a una delimitación de fronteras, entre el Estado y los cultos, entre la política y la esfera espiritual o religiosa, sino que «el Estado promueve la consolidación de valores comunes que fundan los lazos sociales en nuestro país... Es un elemento del pacto republicano» (Informe Comisión Stasi, 1.2.2). Por eso, no puede permanecer pasivo ante cualquier atentado contra este principio. La laicidad significa que el Estado se ocupa de defender los valores comunes de la sociedad cuando sea necesario. En este mismo sentido se expresaba el Ministro del Interior, Nicolas Sarkozy, en su audiencia ante la Comisión Stasi: «más que la laicidad —afirmaba—, lo que está en juego es nuestra concepción de la República». Vemos aquí cómo, al hilo de la explicación del contenido de la laicidad, aparece de nuevo con gran fuerza la cuestión de la religión civil republicana, a la que me refería al comentar la Circular Bayrou.

Por otro lado, según se desprende del Informe, no es una laicidad antirreligiosa o de combate. La laicidad cristalizada en la Ley de 1905 surge por oposición al clericalismo de la Iglesia católica. Pero «ya han pasado los tiempos de la laicidad de combate» (Informe Comisión Stasi, 2.3). La laicidad combativa que ha predominado en otros momentos de la historia ha sido la respuesta a la oposición por parte de autoridades políticas y religiosas al pluralismo en la esfera espiritual. Ahora, tras un siglo de inmigración, las circunstancias han cambiado y la sociedad francesa se ha convertido en una sociedad diversa, de manera especial en el ámbito espiritual o religioso. Por eso, Sarkozy señalaba ante la Comisión que «la laicidad es el reconocimiento de la necesidad que tiene el ser humano de esperar y creer, sin tratar de orientar esa necesidad hacia una u otra religión, así como del derecho a no creer (...). Mi función no es ignorar, prohibir o privilegiar, sino velar para que cada uno sea libre de elegir su fe y practicar su culto. Éste es el sentido de la neutralidad respecto a las religiones: los mismos derechos para todos, los mismos deberes para todos». A diferencia de 1905, de lo que se trata ahora es de conciliar la unidad con el respeto a la diver- 
sidad, en una sociedad caracterizada por la importancia que ha adquirido el reconocimiento de las opciones individuales. En este contexto, la laicidad, que es «una forma de estructurar la vida en común», adquiere una renovada actualidad. Para responder a los retos actuales, no puede estar a la defensiva. «Para afirmar en este contexto la existencia de valores comunes, es necesaria una laicidad abierta y dinámica, capaz de constituir un modelo atractivo e integrador» (Informe Comisión Stasi, 2.3).

Es una laicidad de carácter republicano e intervencionista, más que liberal. Una sociedad liberal no sólo permite que las personas sigan su propio estilo de vida sin favorecer ninguno de ellos en particular, sino que también les permite el acceso a la información sobre otros estilos de vida (a través de la libertad de expresión) y, de hecho, exige que los ciudadanos conozcan otros estilos de vida (a través de la escolarización obligatoria) y permite que la gente haga una revisión radical de sus convicciones. Pero esto no es posible en el templo de la laicidad que es la escuela pública en Francia. La laicidad es la apertura a los otros, el espíritu de tolerancia, la libertad de conciencia, el pluralismo; nos permite vivir juntos en el respeto a las diferencias, pero aquí la laicidad no es el laisser-faire liberal, sino que exige una intervención positiva del Estado. Éste es el sentido de las prohibiciones. Tal y como señala el Informe, «el Estado promueve la consolidación de valores comunes que sirven de fundamento al vínculo social en nuestro país. Entre esos valores, la igualdad entre el hombre y la mujer, no por ser una conquista reciente, deja de ocupar un lugar importante en nuestro Derecho. $Y$ es actualmente un elemento del pacto republicano». Por eso, llevar símbolos religiosos en las escuelas y en las Administraciones públicas significaría el rechazo de uno de los elementos esenciales del pacto republicano, por el que el Estado tiene que velar activamente. Como señala Sarkozy en su intervención ante la Comisión, llevar ese tipo de símbolos implica afirmar: «me adhiero a todos los valores de la República excepto a la laicidad y no reconozco al Estado el derecho a imponerme esa restricción». El Estado no puede ser pasivo frente al ataque a ese principio, sino que a partir de una visión fuerte de la ciudadanía, que trasciende las pertenencias comunitarias, confesionales o étnicas, la laicidad crea al Estado obligaciones respecto de los ciudadanos; fundamentalmente, la obligación de proteger su libertad de conciencia.

La laicidad del Informe de la Comisión Stasi opta, así, por la defensa de la autonomía individual frente al comunitarismo. «El Estado laico protege al individuo; protege la libertad de escoger o no una opción espiritual o religiosa y de cambiar de religión o de abandonar sus creencias» (Informe Comisión Stasi, 2.2.1). Asegura que ningún grupo, ninguna comunidad, pueda imponer a nadie una pertenencia o una identidad confesional en razón de sus orígenes. El Estado laico protege a todas las personas, mujeres y hombres, contra toda presión, física o moral, ejercida al amparo de cualquier prescripción espiritual o religiosa. La defensa activa de la libertad de conciencia individual contra todo proselitismo viene a 
completar las nociones de separación y neutralidad, centrales en la Ley de 1905, y esta exigencia se aplica en primer lugar a la escuela, donde los alumnos deben poder instruirse en un clima de serenidad a fin de acceder a la autonomía de juicio.

El Informe considera que una expresión ostentosa y con una finalidad proselitista de las propias creencias, como es el velo, constituye una amenaza para los derechos de la persona y las libertades públicas. Además, el velo contradice la igualdad entre hombres y mujeres. Es una fuente de conflictos y va en contra de la misión de la escuela, que debe ser un espacio de neutralidad y de desarrollo de la conciencia crítica.

Al mismo tiempo, el Informe señala que la preservación comunitaria de la diferencia cultural o religiosa no constituye un valor absoluto. Por eso, el Estado se compromete a tratar por igual a todas las religiones, pero no a promover la pervivencia y el desarrollo de ninguna de ellas.

De lo dicho hasta ahora se desprende que la definición de la Comisión Stasi incluye los dos aspectos de la laicidad que hemos ido viendo en las declaraciones anteriores: libertad de conciencia y libertad de pensamiento. ¿Por qué, entonces, recomienda prohibir por ley los signos religiosos en las escuelas y en las Administraciones públicas? La razón fundamental apela al orden y a la unidad de la República, a la comunidad de destino que es Francia, sólo realizable si se reservan las manifestaciones de la diversidad cultural y religiosa al espacio de la vida privada. Por eso, una vez oídos los argumentos de unos y de otros, la Comisión estima que no se trata de una cuestión de libertad de conciencia, como habían señalado las primeras declaraciones, sino de orden público. Son el orden público, la comunidad de valores y la autonomía de juicio los que justifican la prohibición. Pero la norma debe entenderse como una oportunidad de integración, como una regla para vivir en comunidad, no únicamente como una prohibición ${ }^{6}$. La laicidad es entendida, entonces, como un medio para lograr la integración social de la diversidad, la convivencia pacífica con la diferencia.

La laicidad significa aquí universalidad frente a la particularidad, neutralidad frente a la diversidad procedente del multiculturalismo. Es la afirmación de un estado universal en el que todos puedan reconocerse, incompatible con cualquier privilegio otorgado a una opción espiritual particular. Las diferencias no se niegan, sino que pueden asumirse y vivirse libremente en la esfera privada. Y significa también autonomía del juicio de cada ciudada-

\footnotetext{
6 El Informe de la Comisión Stasi sobre la laicidad como estrategia de integración y la consiguiente prohibición de los símbolos religiosos en las escuelas y Administraciones públicas han desatado una gran cantidad de críticas, en las que ahora no voy a entrar, por parte de dirigentes religiosos y de asociaciones de defensa de los derechos humanos. Los principales argumentos apuntan que supondría una estigmatización de los musulmanes, llevaría a una exacerbación del sentimiento antirreligioso, impulsaría la desescolarización y propagaría una imagen exterior de una Francia contraria a las libertades fundamentales.
} 
no, alimentada por una instrucción laica. Descansa, entonces, en dos principios esenciales: la igualdad de los ciudadanos política, simbólica y espiritual, y la libertad de pensamiento. En ningún caso significa hostilidad hacia ninguna religión, ni hacia la religión en general.

En esta línea se expresaba el Presidente de la República, Jacques Chirac, en el discurso de presentación del Informe de la Comisión Stasi el 17 de diciembre de 2003: «La laicidad forma parte de nuestras tradiciones. Es un elemento central de la identidad republicana. No se trata hoy en día de refundirla o de modificar sus fronteras ,sino de darle vida manteniéndonos fieles a los equilibrios que hemos sabido inventar y a los valores republicanos. Todos los niños de Francia, independientemente de su historia, origen o credo, son las hijas y los hijos de la República. Y todos deben ser reconocidos como tal tanto en el derecho como, sobre todo, en los hechos. Velando por el respeto de esta exigencia, redefiniendo nuestra política de integración y aplicando nuestra capacidad para dar vida a la igualdad de oportunidades, devolveremos toda su vitalidad a nuestra cohesión nacional. Es la neutralidad del espacio público la que permite a diferentes religiones coexistir en armonía».

En ese mismo discurso, Chirac anuncia la intención de elaborar un proyecto de Ley sobre los símbolos religiosos recogiendo las recomendaciones de la Comisión Stasi. El proyecto de Ley sobre los símbolos religiosos fue aprobado en el Congreso de los Diputados el 10 de febrero de 2004, con 496 votos a favor — de la UMP y del PS-, 36 en contra y 31 abstenciones ${ }^{7}$. Ha entrado en vigor el 1 de septiembre de 2004.

\section{CONCLUSIÓN}

Podríamos concluir tratando de dar respuesta a las siguientes cuestiones: ¿Se encuentra realmente amenazada la laicidad, base de la unidad republicana, en Francia? ¿Es la laicidad la mejor manera de alcanzar la integración y la cohesión social? Reflexionando sobre el tópico que alienta las primeras batallas por la laicidad, «le cléricalisme, voilá l'enemi», Jean Baubérot apunta: «ésta es la consigna de la laicidad militante. Pero ¿quiénes son los nuevos clérigos? ¿Quiénes son los que constituyen una amenaza concreta para la libertad de pensamiento? ¿Lo son las religiones organizadas o, más bien, los nuevos "clérigos" defensores del neoliberalismo a ultranza?» (Baubérot, 1990).

\footnotetext{
7 Sin embargo, una vez aprobada la Ley, el propio Bernard Stasi manifestaba su desacuerdo con la iniciativa, puesto que de todas las propuestas que hizo la Comisión sólo ha salido adelante la prohibición de los signos religiosos. Pero, quizá por las circunstancias que dan lugar a la creación de la Comisión, el conflicto planteado por el velo islámico, no se han tenido en cuenta otras recomendaciones de carácter integrador, como la enseñanza del hecho religioso o la formación de imanes a cargo del Estado.
} 
Un siglo después de la Ley de 1905, Francia se enfrenta con las disfunciones generadas por un neoliberalismo que socava los fundamentos del pacto republicano que funda la comunidad francesa. ¿Son realmente una amenaza para ese pacto las pocas alumnas que acuden a la escuela con la cabeza cubierta? ¿O, más bien, las discriminaciones, los guetos, el paro y todos aquellos que quedan excluidos de las reformas sociales? Como señalaba recientemente Alain Gresh, redactor jefe de Le Monde Diplomatique, «la República francesa debe ser laica y social. Será laica en la medida en que sea social» (Gresh, 2003: 19). Dicho con otras palabras, el fondo del problema no es tanto una cuestión de identidad como de exclusión social; es más una «demanda de redistribución» que una «demanda de reconocimiento», utilizando la contraposición de Nancy Fraser (2003). Por eso, el problema no se arregla con la prohibición del velo, sino con reformas sociales. Lo que ha sucedido en el conflicto sobre los símbolos religiosos es una «etnicización en el tratamiento de los problemas sociales» (Cesari, 2001: 125). El debate sobre el hiyab en Francia esconde la realidad del problema, que radica en el desempleo (que ronda el $40 \%$ entre los jóvenes argelinos), la pobreza, la falta de integración y el racismo.

No se puede focalizar la integración de los inmigrantes en los aspectos culturales, lo que quizá constituye el defecto fundamental de la estrategia de la laicidad. La integración de los inmigrantes en nuestra sociedad no depende tanto de los aspectos culturales, no es tanto una cuestión de adaptación cultural como, sobre todo, un proceso de equiparación de derechos y deberes, de desarrollo de una auténtica igualdad de oportunidades y de trato, de acceso a un estatus laboral normalizado y a los cauces de participación habituales con los que cuenta la sociedad. En las condiciones legales y sociolaborales de los inmigrantes se encuentra la clave de muchos de los problemas de integración y convivencia, y en esta dirección deben apuntar las soluciones, sin distraer la atención del problema fundamental, dirigiéndola hacia la cuestión de los símbolos religiosos.

De hecho, lo que se ha producido en Francia es una superposición de lo social a lo identitario, en el sentido de que el comunitarismo y las identidades colectivas cumplen una función de refugio ante la marginación social. Y la cuestión del velo ha sido la instrumentalización de un signo religioso para una reivindicación social. Por eso, el problema no se resolverá a base de leyes que prohíban las manifestaciones religiosas, sino mejorando sus condiciones de vida y de promoción social.

En esta misma línea, considero que el principal problema que plantea esta cuestión es la discriminación de la mujer, y no el pañuelo como signo religioso. Si de lo que se trata es de combatir la subordinación de la mujer, quizá más eficaz que la prohibición del símbolo sea una educación prolongada y una mejora de sus condiciones sociolaborales. Pero ¿se corrige la discriminación prohibiendo el velo? ¿Se ataca a la discriminación eliminando aquello que sólo es un símbolo externo de la misma? 
Por ello, la tendencia a «restablecer el orden» en las escuelas choca con la falta de proyectos para integrar a los estudiantes que sean expulsados en aplicación de la Ley. Desde 1989, en que se produjeron las tres primeras expulsiones de chicas por no retirarse el velo, el goteo de exclusiones no ha cesado. Las estadísticas son inseguras, pero se sabe que muchas de las adolescentes expulsadas de la escuela no continúan sus estudios. A diferencia de las confesiones cristiana y judía, que han organizado escuelas propias, no hay colegios musulmanes en Francia. Las chicas musulmanas expulsadas sólo pueden continuar estudiando a base de cursos a distancia o con la ayuda de profesores a domicilio. Éste es el riesgo en que incurren las estudiantes que lleven el velo a partir de ahora, si persisten en hacerlo. Por eso, si se impide la escolarización de una niña por llevar la cabeza cubierta, se está reforzando su situación de discriminación, al negarle los instrumentos que podrían ayudarle a superar esa condición en el futuro.

En este sentido, uno de los riesgos que puede tener su prohibición en las escuelas públicas es la proliferación de escuelas privadas musulmanas, en las que las chicas ya no tendrán ni siquiera la posibilidad de decidir por sí mismas quitarse el velo, porque allí no se lo permitirán. El efecto inmediato de la prohibición es que se refuerza el simbolismo identitario del velo ${ }^{8}$.

Por otra parte, lo más preocupante de la cuestión del velo no es la prenda de vestir, sino su significado. No sólo su significado religioso, la sumisión de la mujer, al que ya he aludido, sino su significado político-religioso. El velo es un medio de expresión de carácter culturalreligioso de un problema social, que es la situación de marginación en la que viven una gran parte de los musulmanes en Francia, y su importancia radica en que un problema social se transforma en una cuestión de principios, en un conflicto entre Islam y democracia, entre el Corán y la Constitución, de difícil negociación.

Finalmente, habría que destacar la entronización de la religión civil republicana en el discurso acerca de la integración de la diversidad religiosa y cultural. La unidad de la ciudadanía republicana ha adquirido un valor absoluto, cuasi-religioso, al que se han subordinado otras cuestiones. Como señala Kymlicka, «el temor a que las minorías nacionales sean desleales (o simplemente apáticas) continúa inhibiendo la discusión sobre la justicia de estas reivindicaciones» (Kymlicka, 1997: 88).

\footnotetext{
8 De hecho, la Unión de Organizaciones Islámicas de Francia (UOIF), próxima a los Hermanos Musulmanes, difundió a principios del mes de julio del año 2004 una carta a los musulmanes en la que exhorta a las alumnas de esta religión a presentarse en los colegios con la vestimenta que hayan elegido y se compromete a ayudarles en caso de que los centros interpreten la Ley de forma demasiado estricta. Esta carta no es un llamamiento incendiario, sino una incitación a las familias para que las mujeres no abandonen los estudios, sin renunciar a vestir como quieran. La organización anuncia que, en caso de expulsión, buscará la manera de apoyar a las niñas afectadas para poder continuar con sus estudios.
} 


\section{REFERENCIAS}

BAUBÉROT, J. (1990): Vers un nouveau pacte lä̈que?, Seuil, París.

- (2001): «La laïcité comme pacte laïque», en J. Baudouin y Ph. Portier (eds.), La laïcité. Une valeur d'ajourd'hui? Contestations et renégotiations du modèle français, Presses Universitaires de Rennes, Rennes, pp. 39-50.

BAUMANN, G. (2001): El enigma multicultural. Un replanteamiento de las identidades nacionales, étnicas y religiosas, Paidós, Barcelona.

CESARI, J. (2001): «L'unité républicaine menacée par les ideologies multiculturelles», en J. Baudouin y Ph. Portier (eds.), La laïcité. Une valeur d'ajourd'hui? Contestations et renégotiations du modèle français, Presses Universitaires de Rennes, Rennes, pp. 117-131.

CHERIFI, H. (2001): Entrevista publicada en La Croix, 24 de octubre.

Circular Bayrou, del 20 de septiembre de 1994 (www.ladocumentation.francaise.fr).

Circular Jospin, del 12 de diciembre de 1989 (www.ladocumentation.francaise.fr).

Dictamen del Consejo de Estado de 27 de noviembre de 1989 (www.ladocumentation.francaise.fr).

FRASER, N./HONNETH, A. (2003): Umverteilung oder Annerkennung?, Suhrkamp, Frankfurt.

GRESH, A. (2003): Le Monde Diplomatique, septiembre.

Informe de la Comisión Stasi sobre la laicidad, Le Monde, 12 de diciembre de 2003.

KYMLICKA, W. (1997): Ciudadanía multicultural, Paidós, Barcelona.

LANG, J. (2003): Entrevista publicada en L'Express, 30 de abril.

POULAT, E. (1987): Liberté-laïcité, Cujas-Cerf.

- (2003): Entrevista publicada en Le Monde, 12 de diciembre.

RAMADAN, T. (2002): El Islam minoritario. Cómo ser musulmán en una Europa laica, Bellaterra, Barcelona.

SAMADI, N. (2003): «L'islam, les jeunes et la République», Boletín de ARELC, mayo. 